\title{
Cataract surgery through the small pupil
}

\section{Eung Suk Kim' \\ Sang Beom Han² \\ Seung Jun Lee ${ }^{2}$ \\ Moosang $\mathrm{Kim}^{2}$}

'Department of Ophthalmology, Kyung Hee University Hospital, Kyung Hee University, Seoul, ${ }^{2}$ Department of Ophthalmology, School of Medicine, Kangwon National University,

Chuncheon, Korea
This article was published in the following Dove Press journal:

Clinical Interventions in Aging

4 October 2016

Number of times this article has been viewed

\section{Dear editor}

We read with interest the article by Papaconstantinou et al ${ }^{1}$ entitled "Safety and efficacy of phacoemulsification and intraocular lens implantation through a small pupil using minimal iris manipulation". In their study, the authors compared the results of phacoemulsification through a small pupil using minimal iris manipulation versus phacoemulsification through a well-dilated pupil. They concluded that phacoemulsification through a small pupil using minimal iris manipulation can be safe and it exhibits the same results as those obtained with phacoemulsification through normal pupils. We congratulate the authors for their lightening study and would like to make some contributions and report a contradiction in the study.

Small pupils present a significant challenge for the cataract surgeon. Small pupils can increase the risk of complications during and after any surgical procedure. A pupil that fails to dilate can yield a poor capsulotomy, which makes cataract removal more difficult and might result in iris trauma, anterior capsular tear, posterior capsular rupture, vitreous loss, increased inflammation, irregular pupil shape, and photophobia. The experienced surgeon can simply ignore pupil size and perform the procedures of phacoemulsification through the small pupil, but this may result in the inadvertent complications described. Thus, we cannot recommend the phacoemulsification through a small pupil using minimal iris manipulation.

Most of small pupil enlargement techniques can be grouped into one of the following categories: viscomydriasis, ${ }^{2}$ surgical (papillary membrane removal, multiple partial sphincterotomies, etc), ${ }^{3}$ stretching (iris retractors, bimanual dilatation, etc), ${ }^{4}$ and ring expanders. ${ }^{4}$ Some of these methods are associated with bleeding, permanent loss of iris sphincter function, and abnormal pupil shape postoperatively. Therefore, we recommend the injectable ring expander (Figure 1). Ring expander has several advantages over traditional iris retractors. Implantation and explantation are performed
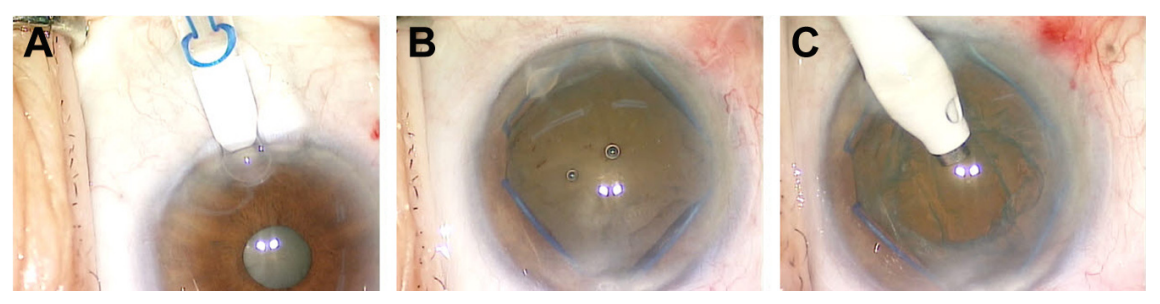

Figure I Mechanical dilation with ring expander.

Notes: The ring expander was introduced to the anterior chamber with an injector (A). The ring expander was placed on the pu-pillary margin (B). Phacoemusification of lens was performed (C). 
with an injector and are relatively simple. Other advantages of the ring expander include lack of any sharp or pointed ends that can damage intraocular tissue and retention of iris tissue in the right plane without forward bunching, thus giving adequate anterior chamber space for performing phaco maneuvers.

\section{Disclosure}

The authors report no conflicts of interest in this communication.

\section{References}

1. Papaconstantinou D, Kalantzis G, Brouzas D, et al. Safety and efficacy of phacoemulsification and intraocular lens implantation through a small pupil using minimal iris manipulation. Clin Interv Aging. 2016; 11:651-657.

2. Jhanji V, Sharma N, Vajpayee RB. Management of intraoperative miosis during pediatric cataract surgery using Healon 5. Middle East Afr J Ophthalmol. 2011;18(1):55-57.

3. Kershner RM. Management of the small pupil for clear corneal cataract surgery. J Cataract Refract Surg. 2002;28(10):1826-1831.

4. Akman A, Yilmaz G, Oto S, Akova YA. Comparison of various pupil dilatation methods for phacoemulsification in eyes with a small pupil secondary to pseudoexfoliation. Ophthalmology. 2004;111(9):1693-1698. 


\section{Authors' reply \\ G Kalantzis \\ D Papaconstantinou \\ D Brouzas \\ A Kontaxakis \\ C Koutsandrea \\ A Diagourtas \\ Ilias Georgalas}

Department of Ophthalmology, National and Kapodistrian University of Athens, Athens, Greece

Correspondence: Ilias Georgalas

Department of Ophthalmology, National and Kapodistrian University of Athens, I54 Mesogeion Avenue, I5400 Athens, Greece

Email igeorgalas@yahoo.com

\section{Dear editor}

We would like to thank Kim et al for their interest in our study and their useful comments.

It is true that performing phacoemulsification through a poorly dilated pupil can be challenging, since visualization of the cataract can be compromised and can lead to insufficient capsulorhexis. Additionally, attempting to operate through an inadequately dilated pupil can result in iris damage, intraocular bleeding, ruptured posterior capsule, vitreous loss, and dropped nucleus. ${ }^{1}$ Most of the cataract surgeons usually decide to mechanically dilate the pupil during surgery by using various devices and techniques. Despite the fact that these methods enlarge the pupil adequately, some are expensive, while others entail extra instrumentation and surgical skills, are time-consuming, and are not always offered in some parts of the world. Additionally, mechanical dilation of the pupil might permanently damage the iris sphincter causing a large atonic pupil. ${ }^{2}$

In our prospective randomized control study, 78 patients with small pupil were involved and our complications were proven not statistically significant in comparison with the control group patients. ${ }^{3}$ However, we stressed the importance of performing such operations by experienced surgeons. With regard to the Kim et al recommendation of the injectable ring expander, it would be of interest that the authors perform a prospective randomized control study in order to prove the efficacy and safety of the injectable ring expander.

\section{Disclosure}

The authors report no conflicts of interest in this communication.

\section{References}

1. Masket S. Cataract surgery complicated by the miotic pupil. In: Buratto L, Osher RH, Masket S, editors. Cataract Surgery in Complicated Cases. Thorofare, NJ: Slack Inc.; 2000:132-135.

2. Vasavada A, Singh R. Phacoemulsification in eyes with a small pupil. J Cataract Refract Surg. 2000;26(8):1210-1218.

3. Papaconstantinou D, Kalantzis G, Brouzas D, et al. Safety and efficacy of phacoemulsification and intraocular lens implantation through a small pupil using minimal iris manipulation. Clin Interv Aging. 2016;11: $651-657$.

Dove Medical Press encourages responsible, free and frank academic debate. The content of the Clinical Interventions in Aging 'letters to the editor' section does not necessarily represent the views of Dove Medical Press, its officers, agents, employees, related entities or the Clinical Interventions in Aging editors. While all reasonable steps have been taken to confirm the content of each letter, Dove Medical Press accepts no liability in respect of the content of any letter, nor is it responsible for the content and accuracy of any letter to the editor.

\section{Publish your work in this journal}

Clinical Interventions in Aging is an international, peer-reviewed journal focusing on evidence-based reports on the value or lack thereof of treatments intended to prevent or delay the onset of maladaptive correlates of aging in human beings. This journal is indexed on PubMed Central, MedLine,
CAS, Scopus and the Elsevier Bibliographic databases. The manuscript management system is completely online and includes a very quick and fair peer-review system, which is all easy to use. Visit http://www.dovepress. com/testimonials.php to read real quotes from published authors. 